\title{
Gene delivery to pancreatic exocrine cells in vivo and in vitro
}

\author{
Isabelle Houbracken ${ }^{1 *}$, Luc Baeyens ${ }^{2}$, Philippe Ravassard ${ }^{3,4,5}$, Harry Heimberg $^{2}$ and Luc Bouwens ${ }^{1}$
}

\begin{abstract}
Background: Effective gene transfer to the pancreas or to pancreatic cells has remained elusive although it is essential for studies of genetic lineage tracing and modulation of gene expression. Different transduction methods and viral vectors were tested in vitro and in vivo, in rat and mouse pancreas.

Results: For in vitro transfection/transduction of rat exocrine cells lipofection reagents, adenoviral vectors, and Mokola- and VSV-G pseudotyped lentiviral vectors were used. For in vivo transduction of mouse and rat pancreas adenoviral vectors and VSV-G lentiviral vectors were injected into the parenchymal tissue. Both lipofection of rat exocrine cell cultures and transduction with Mokola pseudotyped lentiviral vectors were inefficient and resulted in less than 4\% EGFP expressing cells. Adenoviral transduction was highly efficient but its usefulness for gene delivery to rat exocrine cells in vitro was hampered by a drastic increase in cell death. In vitro transduction of rat exocrine cells was most optimal with VSV-G pseudotyped lentiviral vectors, with stable transgene expression, no significant effect on cell survival and about $40 \%$ transduced cells. In vivo, pancreatic cells could not be transduced by intra-parenchymal administration of lentiviral vectors in mouse and rat pancreas. However, a high efficiency could be obtained by adenoviral vectors, resulting in transient transduction of mainly exocrine acinar cells. Injection in immune-deficient animals diminished leukocyte infiltration and prolonged transgene expression.
\end{abstract}

Conclusions: In summary, our study remarkably demonstrates that transduction of pancreatic exocrine cells requires lentiviral vectors in vitro but adenoviral vectors in vivo.

Keywords: Lentiviral vector, Adenoviral vector, Lipofection, Gene transfer, Pancreas, Acinar cell

\section{Background}

The pancreas is a mixed gland with an exocrine and an endocrine component. The exocrine portion makes up more than $95 \%$ of the volume of the pancreas, the endocrine portion $1-2 \%$ [1]. The exocrine pancreas consists of duct, centroacinar and acinar cells, the latter being the most abundant cell type. Acinar cells produce digestive enzymes which they secrete into the duodenum via ducts. In 2 major pancreatic pathologies, pancreatitis and pancreas cancer, the acinar cells are replaced by duct cells, a process termed acinoductal metaplasia [2]. Pancreas cancer has a dismal prognosis: the overall 5year survival rate among patients with pancreas cancer is less than 6\% [3]. Exocrine tumours are the most common form of pancreas cancer from which $95 \%$ are

\footnotetext{
* Correspondence: ihoubrac@vub.ac.be

${ }^{1}$ Cell Differentiation Lab, Diabetes Research Center, Vrije Universiteit Brussel, Laarbeeklaan 103, Brussels B-1090, Belgium

Full list of author information is available at the end of the article
}

pancreatic ductal adenocarcinomas (PDAC). PDAC is thought to arise from ductal precursor lesions, including pancreatic intraepithelial neoplasias (PanIN), which accumulate mutations and become progressively dysplastic, finally forming metastatic tumours [4]. Many recent studies in mice indicate by genetic lineage tracing that at least a part of PDAC and PanIN arise from acinar cells that are reprogrammed into a preneoplastic state [4-8]. Lineage tracing also revealed acinar-to-ductal transdifferentiation, both in caerulein-induced pancreatitis and following pancreatic transforming growth factor alpha overexpression in mice $[9,10]$. In addition, cultured acinar cells from mice [11,12] and humans [13] can transdifferentiate to duct cells.

Also in the context of diabetes mellitus the acinar cells represent an interesting cell population of the pancreas. Diabetes is a group of metabolic diseases characterized by high blood glucose levels which result from defects in insulin secretion, or action, or both. It is a major and

\section{Biomed Central}

(c) 2012 Houbracken et al.; licensee BioMed Central Ltd. This is an Open Access article distributed under the terms of the Creative Commons Attribution License (http://creativecommons.org/licenses/by/2.0), which permits unrestricted use, distribution, and reproduction in any medium, provided the original work is properly cited. 
growing public health problem throughout the world. Beta cell transplantation can restore the functional beta cell mass in diabetic patients but it is seriously hampered by donor shortage. This problem could be solved by generating more beta cells by reprogramming more readily available cell types unaffected by the disease. Acinar cells, the most abundant cell type in the pancreas, represent an attractive source for beta cell replacement therapy. Lineage tracing studies in vitro as well as in vivo have clearly shown that rodent acinar cells can be converted into functional beta cells [14-17]. The ability of acinar cells to become reprogrammed is further supported by acinar transdifferentiation into hepatocytes $[18,19]$ and adipocytes [20]. Their remarkable plasticity and their involvement in 3 major pancreas pathologies make acinar cells a highly interesting cell type. Obviously, an efficient method for gene delivery in pancreatic acinar cells would be a useful tool for genetic lineage tracing, overexpression and knock-down studies, and for gene therapy. Several viral vectors such as adenoviral vectors [13,15,17,21-28], lentiviral vectors [29-34] and adeno-associated viral vectors (AAV) [27,35-37] have been used for gene delivery in pancreas. Although longterm and robust gene transfer in pancreas has already been achieved with AAV vectors and despite several advantages of AAV vectors compared to other vectors such as very low immunogenicity, replication defectiveness, lack of pathogenicity and broad tropism, their major disadvantage of a limited cloning capacity precluded their usage in this study. Because of this characteristic, AAV vectors are less suitable for delivery of larger genes for lineage tracing or overexpression studies. In this comparative study, we opted for lentiviral and adenoviral vectors, next to lipofection. The different transfection/transduction methods were tested in vitro and in vivo in rat and mouse pancreas. We conclude that vesicular stomatitis virus-glycoprotein (VSV-G) pseudotyped lentiviral vectors are the most optimal for in vitro gene transfer, whereas for in vivo transduction of rodent pancreas, adenoviral transduction reached the highest efficiency.

\section{Results}

In vitro transfection of exocrine pancreatic cells is inefficient

Primary cultures of exocrine cells isolated from rat pancreas were transfected with 2 different commercial lipofection reagents, lipofectamine 2000 (cationic liposome) and effectene (a two-component non-liposomal lipid formulation). Transfection was performed on the day of isolation with pEGFP-N2 (day 1) and the efficiency was determined by analyzing the percentage of enhanced green fluorescent protein $(\mathrm{EGFP})+$ cells. While it is reported that cell lines of the exocrine pancreas could be transfected at high yields using lipofectamine 2000 [13,38-41], we found that less than $0.1 \%$ of primary cells were transfected and expressed EGFP (not shown). When varying amounts of plasmid DNA and varying ratios of DNA to effectene reagent were used, EGFP+ cells appeared 24 hours after transfection (Additional file 1: Figure S1) but only $\leq 3.7 \%$ of total cells expressed EGFP on day 8 (Figure 1). A similar efficiency was obtained at earlier time points (Additional file 1: Figure S1).

In vitro transduction of rat exocrine pancreatic cells using mokola and VSV-G pseudotyped lentiviral vectors

The efficiency of Mokola and VSV-G pseudotyped lentiviral vectors was compared in transducing isolated rat exocrine pancreatic cells. Transduction was performed on day 1 (the day of isolation) with a recombinant lentiviral vector that expressed EGFP under the control of the ubiquitous and constitutively active cytomegalovirus (CMV) promoter (LeCMV-EGFP) and whose envelope was pseudotyped with glycoproteins either from Mokola virus (Le ${ }^{\mathrm{Mo}} \mathrm{CMV}-\mathrm{EGFP}$ ) or from VSV (Le ${ }^{\mathrm{VSV}-\mathrm{G}} \mathrm{CMV}-$ EGFP). During culture, EGFP was stably expressed (Figure 2A-F) and on day 8, the fraction of EGFP+ cells was counted at different MOI's (Figure 2G). The efficiency to transduce isolated rat exocrine cells with Le ${ }^{\text {VSV-G }}$ CMV-EGFP was 8 to 11 times higher than with Le ${ }^{\mathrm{Mo}} \mathrm{CMV}-\mathrm{EGFP}$ at multiplicity of infection (MOI) 5 and MOI 10. Transduction with Le ${ }^{\mathrm{VSV}-\mathrm{G}} \mathrm{CMV}-\mathrm{EGFP}$ at MOI of 50 resulted in $41.9 \pm 2.6 \%$ EGFP+ cells on day 8 (Figure 2 F,G).

\section{Comparison of in vitro adenoviral and lentiviral transduction of rat exocrine cells}

To compare the transduction efficiency of adenoviral (AdCMV-EGFP) or lentiviral (Le $\left.{ }^{\mathrm{VSV}-\mathrm{G}} \mathrm{CMV}-\mathrm{EGFP}\right)$ vectors, rat exocrine pancreatic cells were transduced for 4 hours on day 1 (the day of isolation). After the 4 hours transduction period, EGFP was already weakly detectable in adenovirally transduced cells (Additional file 2: Figure S2), whereas no EGFP was observed in the lentivirally transduced cells on day 1 (not shown). The number of EGFP+ cells and the amount of protein per cell increased with increasing MOI's (Additional file 2: Figure S2). Lentiviral expression of EGFP reached a plateau only at day 3 (Figure 3G). During the first days following transduction, adenoviral transduction of rat exocrine cells resulted in high efficiencies and a very high level of transgene expression, even at MOI 1, as compared to Le ${ }^{\mathrm{VSV}-\mathrm{G}} \mathrm{CMV}-\mathrm{EGFP}$ (Figure 3). However, from day 4 on, massive cell death occurred in the adenovirally transduced cells and the formation of monolayers was disturbed (Figure 3C-E). On day 8, only $31.7 \pm 5.3 \%$ $(n=3)$ of the adenovirally transduced cells survived, while 


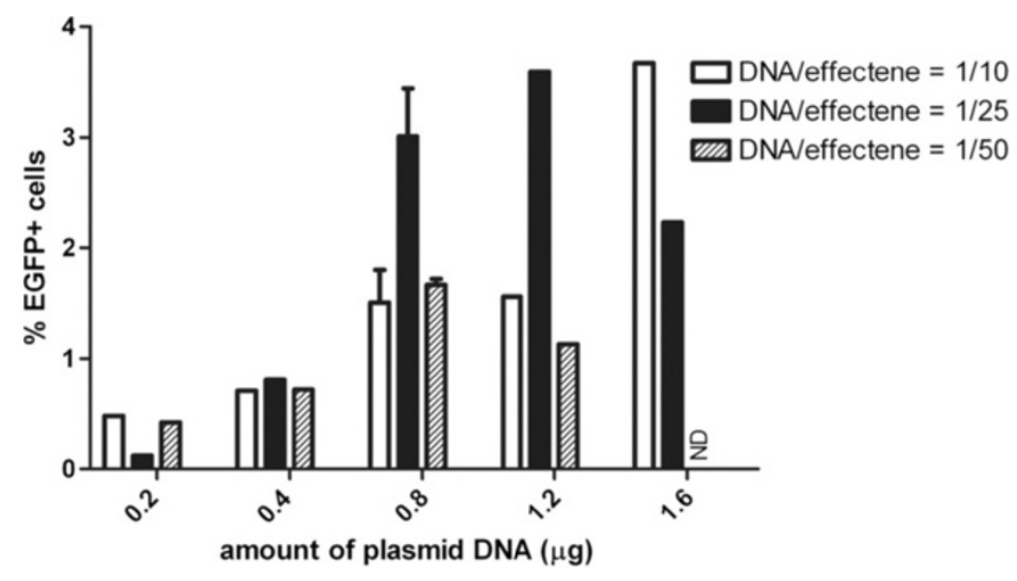

Figure 1 Transfection of isolated rat exocrine pancreas cells with effectene. Quantification of the percentage EGFP expressing cells on day 8 in culture after transfection of rat exocrine pancreas on day 1 with pEGFP-N2 and effectene with varying amounts of plasmid DNA and ratios of DNA/effectene.

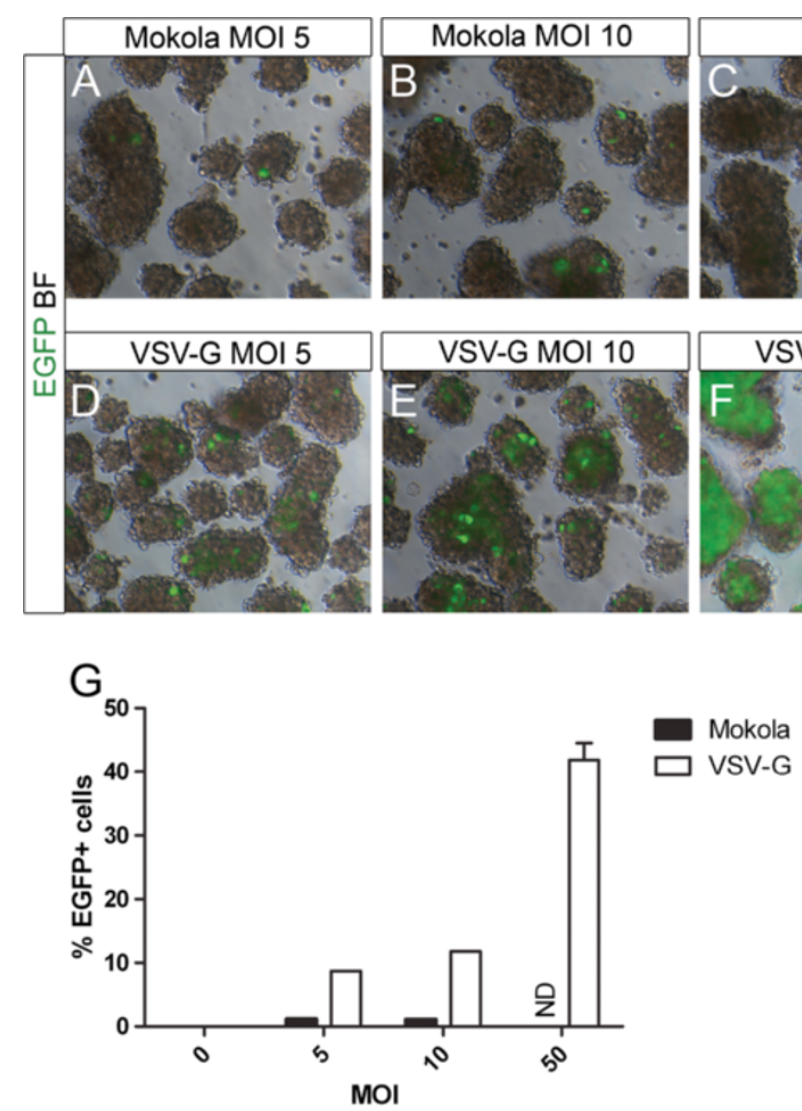

Figure 2 Transduction of isolated rat exocrine pancreas cells using Mokola and VSV-G pseudotyped lentiviral vectors. (A-F) Day 3 in

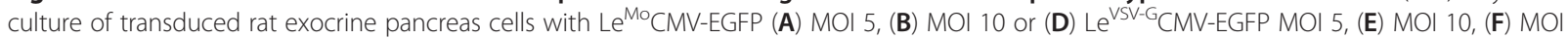
50. (C) Untransduced cells showed no fluorescence. The expression of the reporter increased with higher MOI and was better in Le ${ }^{\text {VSV-G} C M V-E G F P ~}$ as compared to Le ${ }^{\mathrm{Mo}} \mathrm{CMV}$-EGFP. Merged pictures of bright field and green fluorescence. (G) Quantification of the percentage of EGFP expressing cells on day 8 in culture after transduction with Le ${ }^{\mathrm{Mo}} \mathrm{CMV}$-EGFP or Le ${ }^{\mathrm{VSV}-G} \mathrm{CMV}$-EGFP of rat exocrine pancreas on day 1. 

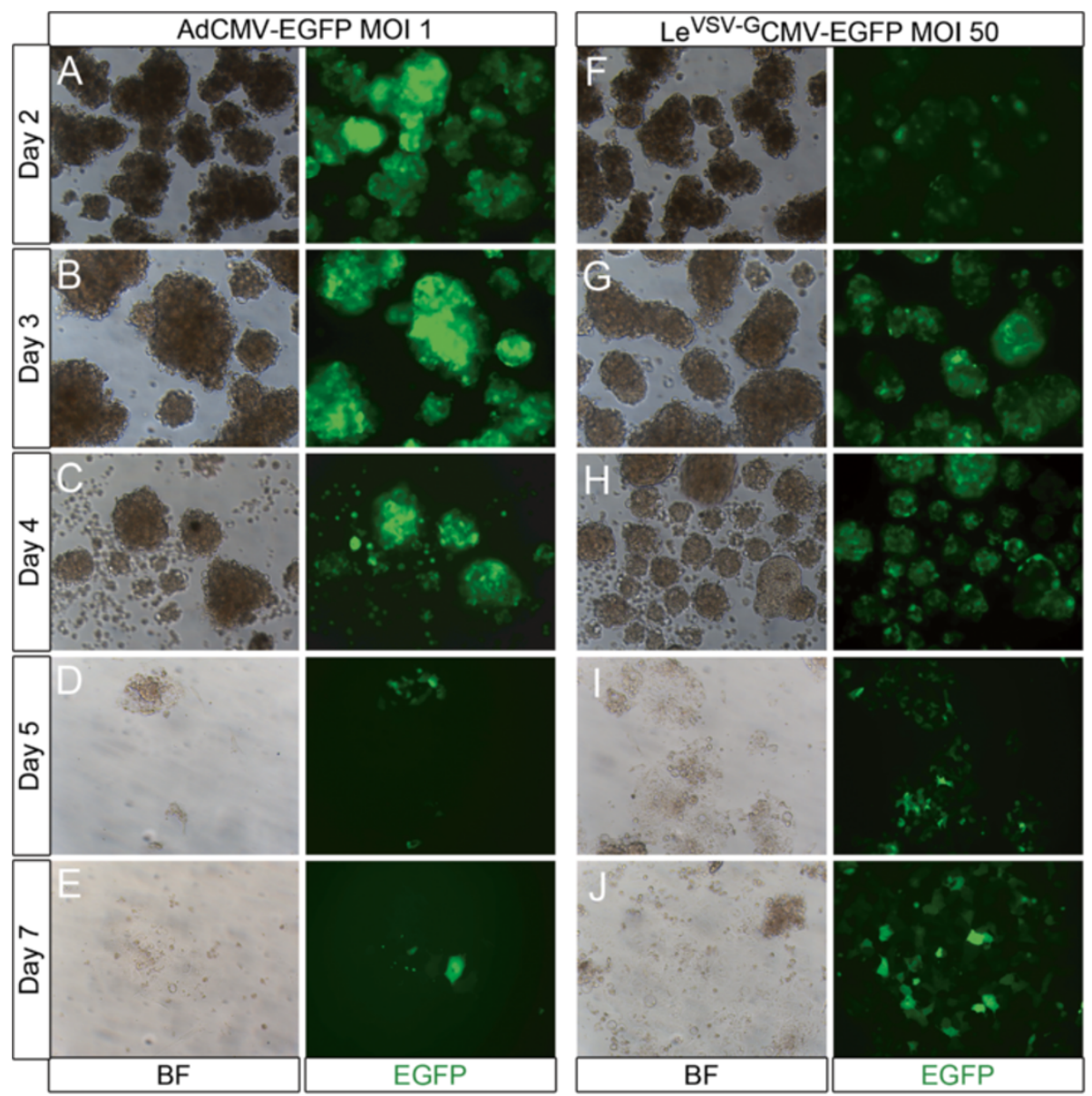

Figure 3 Culture of AdCMV-EGFP and Le ${ }^{\text {VVV-G}}$ CMV-EGFP transduced rat exocrine pancreas cells. (A-J) Culture of rat exocrine pancreas cells

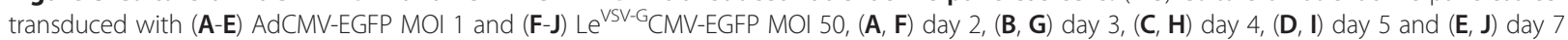
in culture. Adenoviral transduction resulted in higher transduction efficiencies and higher levels of EGFP expression on (A) day 2 and (B) day 3 , when compared to the lentiviral vectors (F-G). However, from $(\mathbf{C})$ day 4 on, massive cell death occurred in the adenovirally transduced condition and the monolayer formation was disturbed. On the contrary, the cell viability in lentivirally transduced cells remained normal and they had a strong and stable expression of the transgene.

the viability of cells transduced with Le ${ }^{\mathrm{VSV}-\mathrm{G}} \mathrm{CMV}-\mathrm{EGFP}$ was comparable to that of non-transduced cells and showed normal monolayer formation and stable transgene expression (Figure 3F-J).

\section{In vivo transduction of pancreatic cells with lentiviral vectors}

To investigate the efficiency of in vivo transduction with

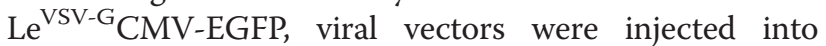
the pancreatic parenchyma of CD1 mice $(n=5)$. A range of $0-10^{7}$ transducing units (TU) was used. Injection of the lectin wheat germ agglutinin coupled to tetramethyl rhodamine isothiocyanate (WGA-TRITC) was previously shown to result in specific binding to acinar cells and served as a control for the injection [14]. Pancreata were analysed for lectin labelling and EGFP expression by endogenous fluorescence in cryosections of the pancreas and by immunohistochemistry with anti-green fluorescent protein (GFP) on paraffin sections on day 7 following viral vector injection. Under these conditions pancreas histology remained normal. However, while lectin-bound TRITC was easily detectable, no EGFP could be observed in viral vector-injected pancreata (Additional file 3: Figure S3). Similarly, no EGFP+ cells could be detected 7 days following injection of different amounts of $\mathrm{Le}^{\mathrm{VSV}-\mathrm{G}} \mathrm{CMV}-\mathrm{EGFP}$ in the parenchyme of rat pancreas $(\mathrm{n}=9)$ (between 0 and $4 \times 10^{7} \mathrm{TU}$ ) (not shown). In conclusion, pancreatic cells could not be transduced in vivo by intra-parenchymal administration of lentiviral vectors.

\section{In vivo transduction of pancreatic cells by adenoviral vectors}

In contrast with the previous in vitro observations, in vivo administration of adenoviral vectors into the parenchyma of mouse and rat pancreas resulted in high 
transduction efficiencies. The pancreas of CD1 mice $(\mathrm{n}=14)$ was injected with different amounts of AdCMV-EGFP $\left(0-5 \times 10^{9}\right.$ plaque forming units (Pfu) at multiple sites. Injection of WGA-TRITC was used as a control. Samples were analyzed at day $4(n=6), 7$ $(\mathrm{n}=4), 9(\mathrm{n}=2)$ and $12(\mathrm{n}=2)$ after injection. On day 4 several lobes of the pancreas showed a high expression level of EGFP (Figure 4A). EGFP was already detectable at a dose of $10^{8} \mathrm{Pfu}$ AdCMV-EGFP and continuously increased as higher amounts of adenoviral vectors were used. However, even at the highest dose used, some pancreatic regions remained negative. The expression of transgene peaked on day 4 (Figure $4 \mathrm{~A}$ ) and diminished with time (Figure $4 \mathrm{~A}, \mathrm{C}, \mathrm{E}$ ) to reach zero level at day 12 (not shown). Haematoxylin-eosin stainings showed local inflammation and infiltration of leukocytes on day 4 with a gradual restoration of normal pancreas histology over time (Figure 4B,D,F). Leukocyte infiltration could no longer be detected at day 12 after transduction (not shown).

AdCMV-EGFP $\left(10^{9}-5 \times 10^{9} \mathrm{Pfu}\right.$ in a volume of $200-$ $600 \mu \mathrm{l}$ of physiologic fluid) were injected at multiple sites in the parenchyma of Wistar rat pancreas. Analysis was done at days $3(\mathrm{n}=11), 6(\mathrm{n}=6), 7(\mathrm{n}=3), 8$ $(\mathrm{n}=2)$, and $10(\mathrm{n}=2)$. Immunohistochemical detection of EGFP revealed that the higher the volume, the more epithelial cells were transduced (not shown). At a constant number of viral vectors $\left(5 \times 10^{9} \mathrm{Pfu}\right)$ in a small injection volume $(200 \mu \mathrm{l})$, mesenchymal cells between pancreatic lobes and peripherally located epithelial cells were transduced, whereas with a higher volume $(\geq 400 \mu \mathrm{l})$ a high transduction efficiency was observed in the centre of the pancreatic lobes (not shown). Also, with increasing numbers of adenoviral vectors, increasing numbers of EGFP+ cells were detected, similar to the results seen in mice (not shown). However, some regions remained negative for the transgene as well. As in mice, the reporter expression was maximal on day 3-4 (Figure 4G and not shown) but declined over time more rapidly than in mice (Figure $4 \mathrm{G}, \mathrm{K}$ ) and was completely absent by day 10 (not shown). Clear signs of local inflammation and leukocyte infiltration were present on day 3-4 and gradually decreased with time (Figure 4I,M). Analysis of consecutive sections showed a clear overlap of inflammatory regions and regions expressing EGFP, as expected (not shown). Double immunohistochemical staining for EGFP and amylase revealed that the majority of the transduced cells both in mice and rats are acinar cells. However, also synaptophysin, insulin or glucagon positive islet cells and some keratin 19-positive duct cells were transduced, albeit at a lower efficiency (Figure 5). In summary, injection of
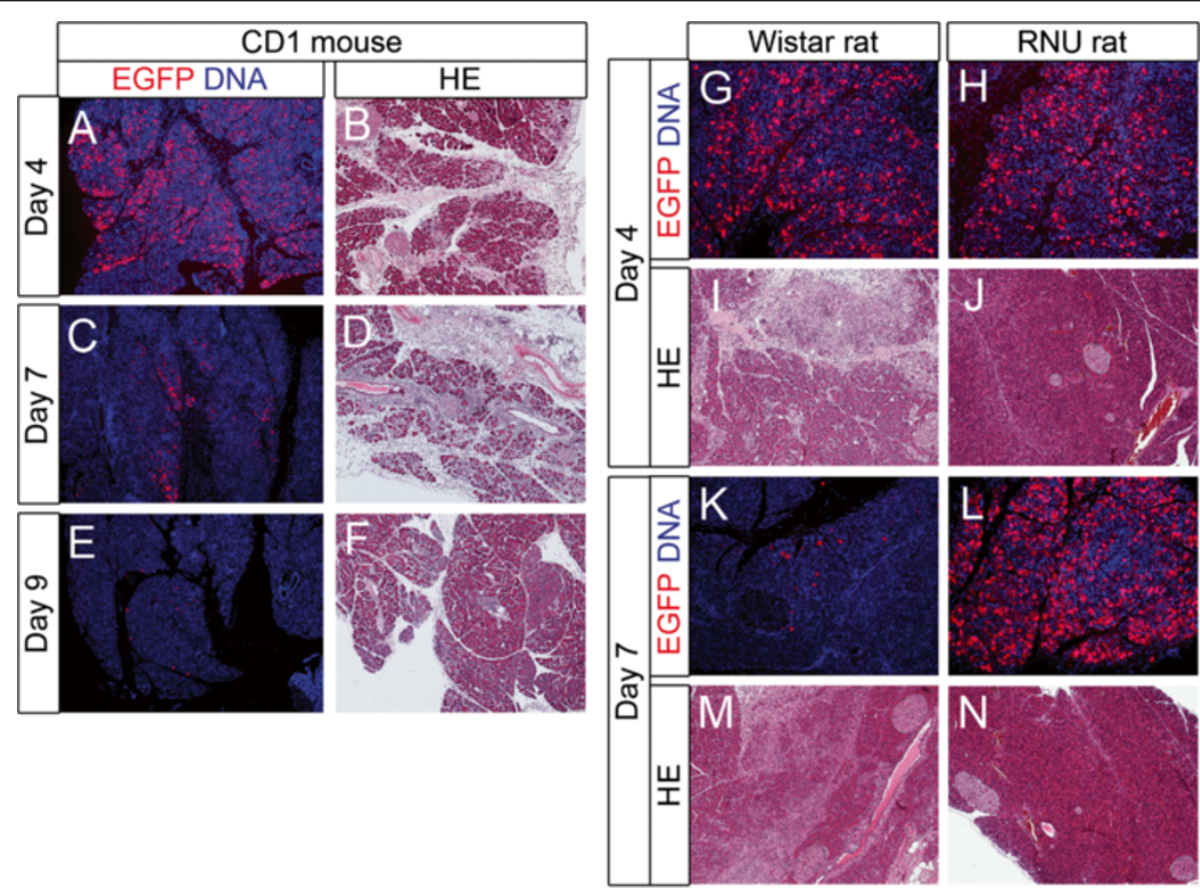

Figure 4 Intra-parenchymal administration of AdCMV-EGFP in mouse and rat pancreas. (A-F) Paraffin sections of the pancreas of CD1 mice injected with (A, B) $10^{9}$ Pfu AdCMV-EGFP analysed on day 4 after injection, (C-F) with $2 \times 10^{9}$ Pfu AdCMV-EGFP analysed (C-D) on day 7 or (E-F) day 9 after injection. (A, C, E) Immunohistochemical staining for EGFP in red and DNA in blue. (B, D, F) Haematoxylin-eosin staining. (G-N) Comparison of intra-parenchymal injection of $5 \times 10^{9}$ Pfu AdCMV-EGFP in (G, I, K, M) immune-competent (Wistar) rats and $(\mathbf{H}, \mathbf{J}, \mathbf{L}, \mathbf{N})$ immune-deficient (RNU) rats, analysed (G-J) on day 4 and (K-N) day 7 after injection. (G-H, K-L) Immunohistochemical staining for EGFP in red and DNA in blue. (I-J, M-N) Haematoxylin-eosin staining. 

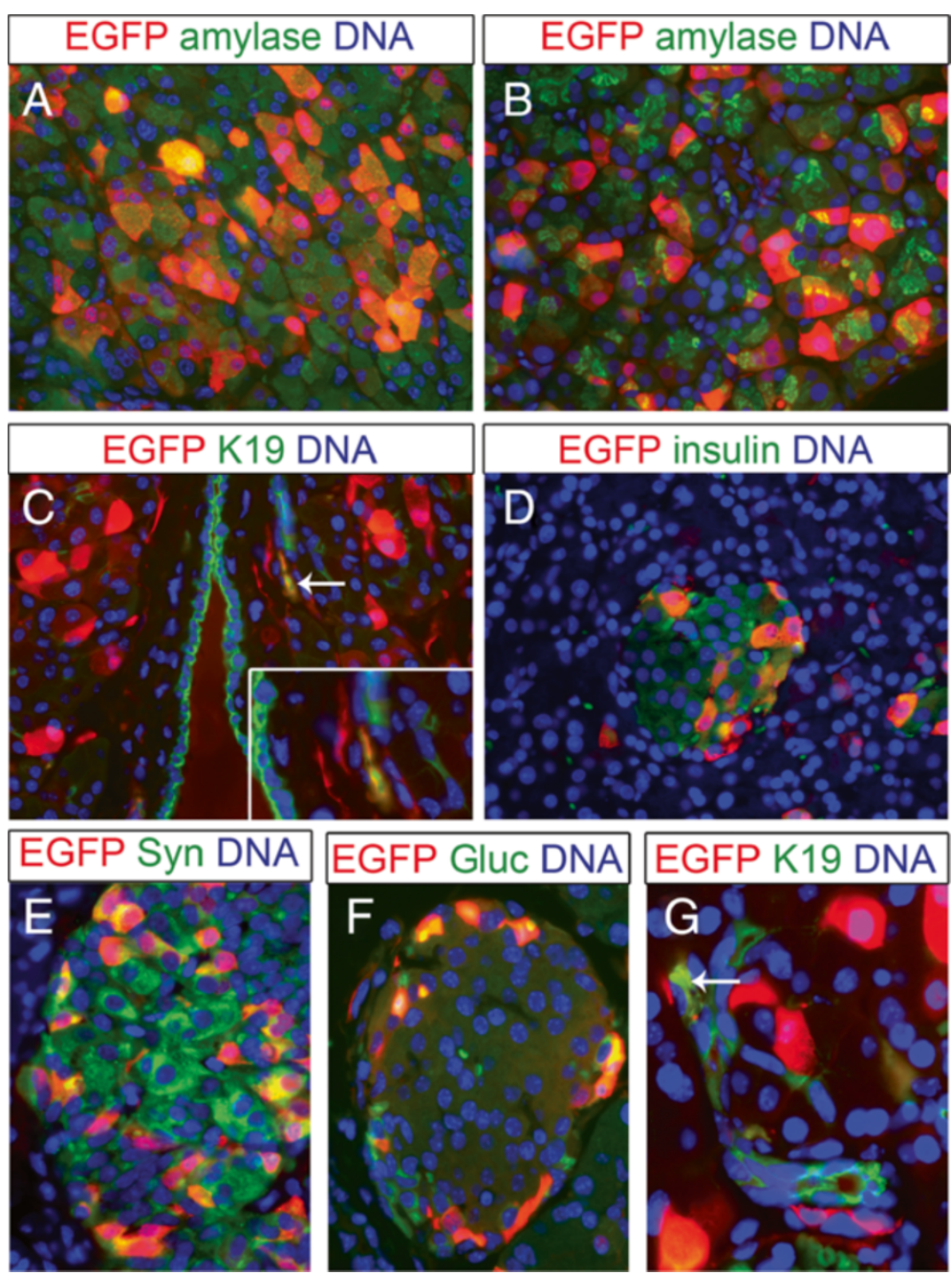

Figure 5 Double immunohistochemical stainings on mouse and rat pancreas injected intra-parenchymal with AdCMV-EGFP. (A-G) Immunohistochemical staining in red for EGFP and in green (A-B) for amylase, (C, E) keratin 19, (D) insulin, (F) glucagon, (G) synaptophysin. (A, C, E-F) Mouse pancreas injected with $10^{9}$ Pfu AdCMV-EGFP. (B, D) RNU rat injected with $5 \times 10^{9}$ Pfu AdCMV-EGFP. (G) Wistar rat injected with $5 \times 10^{9} \mathrm{Pfu}$ AdCMV-EGFP. Arrows indicate double positive cells for EGFP and keratin 19. The inset in $\mathrm{C}$ is a higher magnification.

adenoviral vectors into the parenchyma of rodent pancreas resulted in high transduction efficiency but was accompanied by inflammation, and transgene expression was transient.

\section{In vivo transduction of pancreatic cells from}

\section{immune-deficient rodents with adenoviral vectors}

In order to further improve in vivo transduction of the pancreas, a preliminary study was conducted to compare immune-deficient with immune-competent rodents. Immune-deficient $\mathrm{BALB} / \mathrm{c} \mathrm{Nu} / \mathrm{Nu}$ mice $(\mathrm{n}=4)$ were transduced with $2 \times 10^{9} \mathrm{Pfu}$ of AdCMV-EGFP as described above and were compared to wild-type BALB/ c mice $(n=4)$. Analysis was done at day 4 and at day 7 after injection. The preliminary results indicate that the effects of in vivo pancreas transduction in BALB/c mice were similar as in CD1 mice, with a high level of reporter expression seen on day 4 and less on day 7 , while areas of the transduced pancreas contained inflammatory cells at both time points. Expression of the transgene in $\mathrm{BALB} / \mathrm{c} \mathrm{Nu} / \mathrm{Nu}$ mice on day 4 was comparable with the immune-competent mice. However, at day 7 the expression remained high in the immune-deficient mice and less inflammation was present (not shown). Also in rats a preliminary comparative study was performed of in vivo adenoviral pancreas transduction in immune-competent (Wistar) $(\mathrm{n}=4)$ and immunedeficient (RNU/RNU) animals $(\mathrm{n}=6)$. All animals received $5 \times 10^{9} \mathrm{Pfu}$. Two animals from each group were analyzed on day 4,7 and 14 after injection. The immune-deficient nude rats responded in a similar way as the immune-deficient BALB/c Nu/Nu mice. On day 4 
after transduction there was no difference in the expression of the reporter between immune-deficient rats and immune-competent rats, but pancreata of nude rats contained much less inflammation (Figure 4G-J). On day 7, EGFP expression was low in Wistar rats, whereas it remained high in nude rats (Figure $4 \mathrm{~K}-\mathrm{N}$ ). In nude rats the structure of the pancreas looked normal by day 7 in contrast to Wistar rats (Figure 4M-N). Even after 14 days, expression of the transgene remained high in the nude rats, in contrast to immune-competent animals (not shown). In conclusion, pancreatic cells could be efficiently transduced in vivo by intra-parenchymal administration of adenoviral vectors in rat and mouse pancreas. Highest efficiency was seen in acinar cells, and pancreatic histology was severely affected in normal pancreas but preliminary results indicated nearly normal pancreas histology in immune-deficient animals.

\section{Discussion}

In the search for methods for efficient gene delivery into pancreatic acinar cells, we have investigated different viral and non-viral vectors in vitro and in vivo. Non-viral in vitro transfection of primary exocrine pancreatic cells only reached very low efficiency. Lipofectamine 2000, widely used for transfection of cell lines, has, to our knowledge, not been reported before for transfection of exocrine pancreatic cells. Many studies indicate very high transfection efficiency in rapidly dividing cells [13,38-41]; while in non-dividing human pancreatic islets lipofectamine 2000 resulted in low transfection efficiency [42]. We have demonstrated previously that the exocrine cells in our cultures show a very limited proliferative capacity $[12,43]$, a possible explanation for the observed low transfection efficiency. Another study indicated that trypsin-dispersion of human, rodent and foetal porcine islets increased the efficiency of gene transfer with lipofectamine 2000 [44]. Our unpublished results showed that enzymatic and non-enzymatic dispersion of exocrine cell clusters had a dramatic negative effect on cell survival. The efficiency of transfections with the nonliposomal lipid effectene in primary cells is dependent on the cell type: some primary cell types were reported to express high amounts of the transgene [45-47] while others showed a low efficiency of transfection [48] comparable to our results.

In general, viral vectors are more efficient than non-viral vectors for gene transfer. One way to alter the tropism of a viral vector is pseudotyping, i.e. the incorporation of heterologous envelope proteins in the vector. The most widely used envelope for lentiviral vectors is VSV-G, as it provides the vectors with a very broad host range, and the viral particles can easily be concentrated by ultracentrifugation. For the in vitro transduction of rat exocrine pancreatic cells, we also tested Mokola pseudotyped lentiviral vectors. Mokola is a rabies-related virus and belongs to the family of Rhabdoviridae, as vesicular stomatitis virus does. Mokola pseudotyped lentiviral vectors have been used for the transduction of a variety of cell types, especially brain cells such as neurons, oligodendrocytes, and astrocytes [49-51] but also skeletal and cardiac myocytes [52], satellite cells [53], skin fibroblasts [54], retinal pigment epithelium [55-57] and alveolar epithelium [58]. With the exception of the study of Kobinger et al. [31], in which only a very limited expression of the transgene was shown in human islet cells, they have not been used for the transduction of pancreatic cells. VSV-G pseudotyped lentiviral vectors have also been used for the delivery of genes into various cell types in vitro, including human and rodent pancreatic islets [29,30,32,33]. However, they have not been used for the transduction of pancreatic acinar cells in vitro. We report that VSV-G pseudotyped lentiviral vectors have an 8-11 times higher efficiency to transduce rat exocrine acinar pancreatic cells compared to Mokola pseudotyped lentiviral vectors at comparable MOI. The transgene expression reached a plateau at 48 hours following transduction, remained stable throughout the culture period and did not affect the viability of the cells. Adenoviral vectors, on the other hand, have been reported to induce a very early and titer-dependent expression of the transgene in pancreatic acinar cells in vitro with a very high expression level after 24 hours $[15,21-23,25,28]$, which is comparable to what we observed. Therefore, for short-term culture, adenoviral vectors are very efficient in gene transfer. However, later in culture they induced a considerable amount of cell death. This has not been reported in the abovementioned studies, since the acinar cells were mostly kept in culture only for 24 hours [21-23] and at maximum for 4 days [15].

The results of in vivo intra-parenchymal delivery of lentiviral vectors in the pancreas are in sharp contrast with the high efficiency during in vitro lentiviral transduction. A similar report has been published, in which no significant transduction of the pancreas by intraparenchymal injection of lentiviral vectors was reported [35]. On the contrary, intra-ductal administration of lentiviral vectors in the mouse pancreas efficiently transduced acinar cells [34]. In vivo transduction efficiencies do not always correlate with in vitro efficiencies $[27,35,59]$. The remarkable difference in transduction efficiency of lentiviral vectors in vitro and in vivo might be explained by lentiviral instability in the presence of serum [35,60-63]. Lentiviral vectors also have a relatively large virion size which could affect their capacity to perfuse the tissue [35].

Adenoviral vectors have been used previously to transduce pancreatic cells in vivo via different routes: 
intravenously [24,26], intra-ductally [64], and intraparenchymal [17,27]. Although adenoviral vectors show a high efficiency of transduction, they also elicit an immune response. Our preliminary results in immunedeficient nude mice and rats indicated considerably less tissue inflammation. Similar observations have been reported with Rag -/- immune-deficient mice [17].

Several mechanisms may account for the transient transgene expression following adenoviral transduction, both in vivo and in vitro. The adenoviral episome may be eliminated in cells that are replicating, since it does not integrate into the host genome. Furthermore, acute direct toxicity of adenoviral proteins has been described $[65,66]$. Also, some adenoviral gene products induce apoptosis [67]. Residual expression of adenoviral genes in islet cells in vitro was sufficient to modulate cell death [68]. Moreover, it has been reported that the transgene itself also can induce increased cell death $[66,69]$. However, in the current study the latter is very unlikely since lentiviral overexpression of EGFP did not induce cell death. The presence of inflammatory infiltrates in the pancreas after intra-parenchymal delivery of adenoviral vectors and the increased duration of transgene expression in immune-deficient animals indicate that the elicited immune response limited the transgene expression.

\section{Conclusions}

We demonstrated that VSV-G pseudotyped lentiviral vectors provide the best transduction efficiency with optimal cell viability for in vitro gene delivery to exocrine pancreatic cells as compared to adenoviral vectors, Mokola pseudotyped lentiviral vectors and lipofection. Remarkably, direct intrapancreatic injection of lentiviral vectors in rodents was highly inefficient. For in vivo transduction of rodent pancreas, adenoviral vectors were superior and our preliminary results in immunedeficient animals were very promising . Mainly exocrine acinar cells were targeted. Acinar cells represent an interesting cell type to study in the context of pancreatic pathology and regenerative biology, since their transdifferentiation potential has already been extensively documented [4-11,13-17,19,20]. The gene transfer methods that we have developed in this study will be helpful not only to allow genetic lineage tracing but also for gainand loss-of function studies in order to obtain a better understanding of acinar cell plasticity.

\section{Methods}

Animals

The following animals were used for the in vivo administration of viral vectors: male CD1 mice weighing 38-51 g (Crl:CD1(ICR)) (Charles River Laboratories, L'Arbresle Cedex, France), male BALB/c mice weighing 23-25 g (BALB/cAnNCrl) (Charles River Laboratories), male
BALB/c Nude Mice weighing 21-24 g (CAnN.CgFoxn1nu/Crl) (Charles River Laboratories), male Wistar Han rats weighing 210-350 g (Crl:WI(Han) (Charles River Laboratories), male Rowett nude rats weighing 180-210 g (HsdHan ${ }^{\mathrm{TM}}$ :RNU-Foxn1rnu (Harlan, Horst, the Netherlands)). Male 10-12 week old Wistar rats (Janvier, Le Genest-St-Isle, France) weighing 250-300 g were used for the isolation of cells from the pancreas. Pancreata were partially dissociated with collagenase and exocrine acini were purified by centrifugal elutriation as published before [12]. All animal experimentation was approved by the Ethical Committee of the Free University of Brussels.

\section{Culture procedure}

After isolation, the cell density of the suspension of rat exocrine cells was determined using a haemocytometer. Therefore, a representative sample of the cell suspension was centrifuged, followed by trypsinisation (Sigma) for 5 minutes at $37^{\circ} \mathrm{C}$. The cells were washed with standard medium with $10 \%$ serum (see below) and were then lysed and stained by propidium iodide lyse buffer (sodium citrate $(1 \mathrm{~g} / \mathrm{l})$, propidium iodide $(50 \mathrm{mg} / \mathrm{l})$, tritonX $(0.1 \%))$. The nuclei were counted in a Bürker chamber. The exocrine cells were pre-cultured for 4 days in bacteriological Petri dishes (Nunc, Langenselbold, Germany) in Advanced RPMI-1640 medium (Invitrogen, Merelbeke, Belgium) supplemented with $10 \%$ foetal bovine serum (FBS) (Gibco, Invitrogen), glutamax-I (Gibco, Invitrogen) and penicillin-streptomycin solution (100 U/l - $100 \mathrm{mg} / \mathrm{l}$ ) (Sigma, St Louis, MO, USA) at $37^{\circ} \mathrm{C}$ in a humidified atmosphere of $5 \% \mathrm{CO}_{2}$. Geneticin sulphate $(50 \mu \mathrm{g} / \mathrm{ml})$ (Sigma) was used to suppress fibroblast overgrowth in the culture. Medium was replaced daily during this preculture period. At the end of the preculture, cells were transferred to 24-well plates (Falcon, BD Biosciences, Erembodegem, Belgium) to form adherent cultures. Adherent monolayers were further cultured with RPMI supplemented with 1\% FBS and antibiotics and $50 \mathrm{ng} / \mathrm{ml}$ human recombinant epidermal growth factor (Sigma) [43].

\section{Transfection}

Rat exocrine cells were transfected with pEGFP-N2 on the day of isolation (day 1) using lipofectamine 2000 (Invitrogen) or effectene (Qiagen, Venlo, Netherlands) according to the manufacturer's protocol in suspension 24-well plates (Greiner Bio-one, Frickenhausen, Germany) or $35 \mathrm{~mm}$ suspension dishes (Nunc). After 4 hours transfection with lipofectamine 2000, the medium was changed to the standard medium with antibiotics and the cells were cultured according to the standard protocol. 


\section{In vitro transduction}

After isolation, the rat exocrine cells were transduced by adenoviral or lentiviral vectors (day 1) in minimal amounts of medium without serum for 4 hours in suspension 24-well plates (Greiner Bio-one) or $35 \mathrm{~mm}$ suspension dishes (Nunc). Different multiplicities of infection were used. Then the cells were washed three times and cultured according to the standard protocol.

\section{Viral vector production}

Recombinant replication-deficient adenoviral vectors expressing EGFP (AdCMV-EGFP) were generated following standard techniques as described by $\mathrm{He}$ et al [70]. Therefore the AdEasy ${ }^{\mathrm{TM}}$ adenoviral vector system (Agilent technologies, Diegem, Belgium) was used. The adenoviral plasmids were produced by homologous recombination in electro competent E.coli BJ5183 cells between the adenoviral backbone plasmid vector, pAdEasy-1, and a shuttle vector pAdTrack. pAdEasy-1 contains most sequences from human adenovirus serotype 5 with deletion of the genes E1 and E3; the pAdTrack vector is a shuttle vector for production of EGFP-trackable viral vectors. The adenoviral vectors were then produced by transfection in 293E1 cells [70].

The lentiviral vectors used are third generation lentiviral vectors with as main features: the vectors are self inactivating (SIN) (promoter activity in the U3 region of the long terminal repeat (LTR) has been deleted (DeltaU3)) and they contain the DNA flap region also named Triplex or central purine pyrimidine track (cPPT) that is crucial for optimal transport of the reverse transcribed dsDNA into the nucleus [71]. Recombinant lentiviral vectors (LeCMV-EGFP) were produced by transient transfection of 293T cells according to standard protocols [72] with some modifications. Briefly, 293T cells were cotransfected with the packaging plasmid pCMVdeltaR8.74, the envelope plasmid pMD2.G encoding for VSV-G or Mokola envelope, and the transfer vector pTrip-CMV-EGFP-deltaU3 [73]. After 6-8 h the medium was changed and lentiviral vectors were harvested $48 \mathrm{~h}$ and $72 \mathrm{~h}$ later. Supernatants were treated with DNase (Roche, Vilvoorde, Belgium), filtered through a $0.22-\mu \mathrm{m}$-pore-size filter, and concentrated by ultracentrifugation in a Beckman SW28 rotor (Optima LE-80K ultracentrifuge; Beckman Coulter, Palo Alto, CA) for $90 \mathrm{~min}$ at $22000 \mathrm{rpm}$. After ultracentrifugation, the pellet was resuspended in phosphate buffered saline, divided into aliquots and frozen at $-80^{\circ} \mathrm{C}$ until use. Lentiviral vectors were titrated as described [74].

\section{Microscopy and immunohistochemistry}

Microscopic images were acquired with a Nikon TE2000E microscope using NIS AR2.30 Imaging Software (Nikon France SAS, Champigny-sur-Marne, France) and with a
Leica DM IRBE microscope using Axiovision 3.1 software (Carl Zeiss, Zaventem, Belgium). Pictures were taken from living cell cultures as well as from fixed, stained material.

For in vitro culture, the cells were fixed on day 8 with formaldehyde (Labonord, Templemars, France) for $10 \mathrm{~min}$ at room temperature. The monolayer was covered with Vectashield containing 4',6-diamidino-2-phenylindole (Vector Laboratories, Burlingame CA94010, USA). To determine the efficiency of transfection/transduction, the native fluorescence of EGFP of at least 1000 cells per condition was evaluated.

For immunohistochemistry, the pancreata were fixed with formaldehyde (Labonord, Templemars, France) for $4 \mathrm{~h}$, dehydrated and embedded in paraffin. Paraffin sections of $4 \mu \mathrm{m}$ were cut. Alternatively, the pancreata were fixed for 4 hours in cold $4 \%$ paraformaldehyde (Sigma), soaked overnight in $20 \%$ sucrose solution, embedded in optimal cutting temperature compound (Labonord) and frozen in liquid nitrogen. Frozen sections of $5 \mu \mathrm{m}$ were cut. The indirect method with fluorochrome-labelled secondary antibodies was used. Secondary antibodies directly coupled to tetramethyl rhodamine isothiocyanate, fluoresceinisothiocyanate or cyanine 2 were purchased from Jackson ImmunoResearch Laboratories (West Grove, PA., USA). The primary antibodies were: 1/500 rabbit anti-amylase (Sigma), 1/100 goat anti-GFP (Abcam, Cambridge, UK), 1/3000 rabbit anti-glucagon (Prof. C. Van Schravendijk, Brussels), 1/2000 mouse anti-glucagon (Sigma), 1/3000 guinea pig anti-insulin (Prof. C. Van Schravendijk, Brussels), 1/100 rat anticytokeratin 19 (Hybridoma bank), 1/1000 rabbit polyclonal anti-keratin (Dako, Glostrup, Denmark) and 1/10 rabbit anti-synaptophysin (Novocastra, Zaventem, Belgium).

\section{In vivo transduction}

Mice were anesthetized by i.p. injection with a mixture of ketamine $(75 \mathrm{mg} / \mathrm{kg})$ and medetomidine $(1 \mathrm{mg} / \mathrm{kg})$, rats by i.p injection of Nembutal. Exposure of pancreas was performed via laparotomy through midline incision. The lentiviral and adenoviral vector solutions were microinjected directly into the pancreatic parenchyma at multiple sites. In mouse pancreas, we injected in both head and tail part of the pancreas; in rat pancreas, only injections in the tail part were performed. Injections with wheat germ agglutinin, coupled to tetramethyl rhodamine isothiocyanate (Invitrogen) were used as a control [14].

\section{Additional files}

Additional file 1: Figure S1. Shows images of rat exocrine pancreas cells after in vitro transfection with effectene on day 2 and day 7 in culture. 
Additional file 2: Figure S2. Shows images of rat exocrine pancreas cells immediately after transduction with AdCMV-EGFP with different MOI's.

Additional file 3: Figure S3. Shows immunohistochemistry of mouse pancreas after intra-parenchymal administration of Le ${ }^{\text {VSV-G} C M V-E G F P ~ w i t h ~ o r ~ w i t h o u t ~ l e c t i n . ~}$

\section{Abbreviations}

AAV: Adeno-associated viral vectors; AdCMV-EGFP: Adenoviral vector carrying CMV-EGFP; CMV: Cytomegalovirus promoter; CPPT: Central purine pyrimidine track; EGFP: Enhanced green fluorescent protein; FBS: Foetal bovine serum; GFP: Green fluorescent protein; Le ${ }^{\text {Mo }}$ CMV-EGFP: Mokola pseudotyped

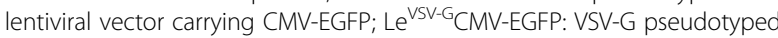
lentiviral vector carrying CMV-EGFP; LTR: Long terminal repeat; MOI: Multiplicity of infection; PanIN: Pancreatic intraepithelial neoplasias; PDAC: Pancreatic ductal adenocarcinomas; Pfu: Plaque forming units; SIN: Self inactivating; TU: Transducing units; VSV-G: Vesicular stomatitis virus-glycoprotein; WGA-TRITC: Wheat germ agglutinin coupled to tetramethyl rhodamine isothiocyanate.

\section{Competing interests}

The authors declare that they have no competing interests.

\section{Authors' contributions}

All authors participated in the conception and design of the study, in the critical revision of the manuscript for important intellectual content, and all authors read and approved the final manuscript. $\mathrm{IH}$ performed the research (acquisition, analysis and interpretation of data), and drafted the manuscript $\angle B O, L B a$ and $H H$ participated in the analysis and interpretation of data and LBo helped in drafting the manuscript.

\section{Acknowledgements}

The authors thank W. Rabiot, E. De Blay, M. Baekeland, J De Jonge, E. Quartier for technical assistance; Prof. Dr. D. Pipeleers and Prof. Dr. K. Thielemans for logistic support; Prof. Dr. I. Rooman, Dr. J. K. Mfopou, Prof. Dr. M. Van De Casteele, Dr. Y Heremans, Dr. S. Bonné for helpful discussions. I Houbracken and $L$ Baeyens are research fellows of the Fund for Scientific Research-Flanders (FWO-Vlaanderen). This work was supported by awards from JDRF, EFSD/Novo Nordisk and Fund for Scientific Research-Flanders.

\section{Author details}

${ }^{1}$ Cell Differentiation Lab, Diabetes Research Center, Vrije Universiteit Brussel, Laarbeeklaan 103, Brussels B-1090, Belgium. ${ }^{2}$ Beta Cell Neogenesis Lab, Diabetes Research Center, Vrije Universiteit Brussel, Laarbeeklaan 103, Brussels B-1090, Belgium. ${ }^{3}$ Université Pierre et Marie Curie-Paris 6, Biotechnology \& Biotherapy Team, Centre de Recherche de I'Institut du Cerveau et de la Moelle épinière (CRICM), UMRS 975, Paris 75013, France. ${ }^{4}$ CNRS, UMR 7225 , Paris 75013, France. ${ }^{5}$ Inserm, U 975, Paris 75013, France.

Received: 25 June 2012 Accepted: 19 October 2012

Published: 22 October 2012

\section{References}

1. Kim SK, Hebrok M: Intercellular signals regulating pancreas development and function. Genes Dev 2001, 15(2):111-127.

2. Lardon J, Bouwens L: Metaplasia in the pancreas. Differentiation 2005, 73(6):278-286

3. Jemal A, Siegel R, Xu J, Ward E: Cancer Statistics, 2010. CA Cancer J Clin 2010, 60(5):277-300.

4. Morris JP, Cano DA, Sekine S, Wang SC, Hebrok M: Beta-catenin blocks Kras-dependent reprogramming of acini into pancreatic cancer precursor lesions in mice. J Clin Invest 2010, 120(2):508-520.

5. De La OJ, Emerson LL, Goodman JL, Froebe SC, Illum BE, Curtis AB, Murtaugh LC: Notch and Kras reprogram pancreatic acinar cells to ductal intraepithelial neoplasia. Proc Natl Acad Sci USA 2008, 105(48):18907-18912.

6. Guerra C, Schuhmacher AJ, Canamero M, Grippo PJ, Verdaguer L, PerezGallego L, Dubus P, Sandgren EP, Barbacid M: Chronic pancreatitis is essential for induction of pancreatic ductal adenocarcinoma by K-Ras oncogenes in adult mice. Cancer Cell 2007, 11(3):291-302.
7. Habbe N, Shi G, Meguid RA, Fendrich V, Esni F, Chen H, Feldmann G, Stoffers DA, Konieczny SF, Leach SD, Maitra A: Spontaneous induction of murine pancreatic intraepithelial neoplasia (mPanIN) by acinar cell targeting of oncogenic Kras in adult mice. Proc Natl Acad Sci USA 2008, 105(48):18913-18918.

8. Shi G, Zhu L, Sun Y, Bettencourt R, Damsz B, Hruban RH, Konieczny SF: Loss of the acinar-restricted transcription factor Mist1 accelerates Kras-induced pancreatic intraepithelial neoplasia. Gastroenterology 2009, 136(4):1368-1378

9. Strobel O, Dor Y, Alsina J, Stirman A, Lauwers G, Trainor A, Castillo CF, Warshaw AL, Thayer SP: In vivo lineage tracing defines the role of acinarto-ductal transdifferentiation in inflammatory ductal metaplasia. Gastroenterology 2007, 133(6):1999-2009.

10. Blaine SA, Ray KC, Anunobi R, Gannon MA, Washington MK, Means AL: Adult pancreatic acinar cells give rise to ducts but not endocrine cells in response to growth factor signaling. Development 2010, 137(14):2289-2296.

11. Means AL, Meszoely IM, Suzuki K, Miyamoto Y, Rustgi AK, Coffey RJ Jr, Wright CV, Stoffers DA, Leach SD: Pancreatic epithelial plasticity mediated by acinar cell transdifferentiation and generation of nestin-positive intermediates. Development 2005, 132(16):3767-3776.

12. Rooman I, Heremans $Y$, Heimberg $H$, Bouwens L: Modulation of rat pancreatic acinoductal transdifferentiation and expression of PDX-1 in vitro. Diabetologia 2000, 43(7):907-914.

13. Houbracken I, Waele ED, Lardon J, Ling Z, Heimberg H, Rooman I, Bouwens L: Lineage Tracing Evidence for Transdifferentiation of Acinar to Duct Cells and Plasticity of Human Pancreas. Gastroenterology 2011, 141(2):731-741. 741e1-4.

14. Baeyens L, Bonne S, Bos T, Rooman I, Peleman C, Lahoutte T, German M, Heimberg $\mathrm{H}$, Bouwens $\mathrm{L}$ : Notch signaling as gatekeeper of rat acinar-tobeta-cell conversion in vitro. Gastroenterology 2009, 136(5):1750-1760. e1713.

15. Minami K, Okuno M, Miyawaki K, Okumachi A, Ishizaki K, Oyama K, Kawaguchi M, Ishizuka N, Iwanaga T, Seino S: Lineage tracing and characterization of insulin-secreting cells generated from adult pancreatic acinar cells. Proc Natl Acad Sci USA 2005, 102(42):15116-15121.

16. Okuno M, Minami K, Okumachi A, Miyawaki K, Yokoi N, Toyokuni S, Seino S: Generation of insulin-secreting cells from pancreatic acinar cells of animal models of type 1 diabetes. Am J Physiol Endocrinol Metab 2007, 292(1):E158-E165.

17. Zhou Q, Brown J, Kanarek A, Rajagopal J, Melton DA: In vivo reprogramming of adult pancreatic exocrine cells to beta-cells. Nature 2008, 455(7213):627-632.

18. Lardon J, De Breuck S, Rooman I, Van Lommel L, Kruhoffer M, Orntoft T, Schuit F, Bouwens L: Plasticity in the adult rat pancreas: transdifferentiation of exocrine to hepatocyte-like cells in primary culture. Hepatology 2004, 39(6):1499-1507.

19. Wu SY, Hsieh CC, Wu RR, Susanto J, Liu TT, Shen CR, Chen Y, Su CC, Chang FP, Chang HM, Tosh D, Shen CN: Differentiation of pancreatic acinar cells to hepatocytes requires an intermediate cell type. Gastroenterology 2010, 138(7):2519-2530

20. Bonal C, Thorel F, Ait-Lounis A, Reith W, Trumpp A, Herrera PL: Pancreatic inactivation of c-Myc decreases acinar mass and transdifferentiates acinar cells into adipocytes in mice. Gastroenterology 2009, 136(1):309-319. e309.

21. Han B, Logsdon CD: Cholecystokinin induction of mob-1 chemokine expression in pancreatic acinar cells requires NF-kappaB activation. Am J Physiol 1999, 277(1 Pt 1):C74-C82.

22. Li C, Chen X, Williams JA: Regulation of CCK-induced amylase release by PKC-delta in rat pancreatic acinar cells. Am J Physiol Gastrointest Liver Physiol 2004, 287(4):G764-G771.

23. Padfield PJ, Elliott AC, Baldassare JJ: Adenovirus-mediated gene expression in isolated rat pancreatic acini and individual pancreatic acinar cells. Pflugers Arch 1998, 436(5):782-787.

24. Pujal J, Huch M, Jose A, Abasolo I, Rodolosse A, Duch A, Sanchez-Palazon L, Smith FJ, McLean WH, Fillat C, Real FX: Keratin 7 promoter selectively targets transgene expression to normal and neoplastic pancreatic ductal cells in vitro and in vivo. FASEB J 2009, 23(5):1366-1375.

25. Simeone DM, Zhang L, Graziano K, Nicke B, Pham T, Schaefer C, Logsdon CD: Smad4 mediates activation of mitogen-activated protein kinases by 
TGF-beta in pancreatic acinar cells. Am J Physiol Cell Physiol 2001, 281(1):C311-C319.

26. Wang $A Y$, Ehrhardt $A, X u H$, Kay MA: Adenovirus transduction is required for the correction of diabetes using Pdx-1 or Neurogenin-3 in the liver. Mol Ther 2007, 15(2):255-263

27. Wang AY, Peng PD, Ehrhardt A, Storm TA, Kay MA: Comparison of adenoviral and adeno-associated viral vectors for pancreatic gene delivery in vivo. Hum Gene Ther 2004, 15(4):405-413.

28. Zhang L, Graziano K, Pham T, Logsdon CD, Simeone DM: Adenovirusmediated gene transfer of dominant-negative Smad4 blocks TGF-beta signaling in pancreatic acinar cells. Am J Physiol Gastrointest Liver Physiol 2001, 280(6):G1247-G1253.

29. Chou FC, Sytwu HK: Overexpression of thioredoxin in islets transduced by a lentiviral vector prolongs graft survival in autoimmune diabetic NOD mice. J Biomed Sci 2009, 16:71.

30. He Z, Wang F, Kumagai-Braesch M, Permert J, Holgersson J: Long-term gene expression and metabolic control exerted by lentivirus-transduced pancreatic islets. Xenotransplantation 2006, 13(3):195-203.

31. Kobinger GP, Deng S, Louboutin JP, Vatamaniuk M, Matschinsky F, Markmann JF, Raper SE, Wilson JM: Transduction of human islets with pseudotyped lentiviral vectors. Hum Gene Ther 2004, 15(2):211-219.

32. Russ HA, Bar $Y$, Ravassard $P$, Efrat $S$ : In vitro proliferation of cells derived from adult human beta-cells revealed by cell-lineage tracing. Diabetes 2008, 57(6):1575-1583.

33. Russ HA, Ravassard P, Kerr-Conte J, Pattou F, Efrat S: Epithelialmesenchymal transition in cells expanded in vitro from lineage-traced adult human pancreatic beta cells. PLoS One 2009, 4(7):e6417.

34. Xu X, D'Hoker J, Stange G, Bonne S, De Leu N, Xiao X, Van de Casteele M, Mellitzer G, Ling Z, Pipeleers D, Bouwens L, Scharfmann R, Gradwohl G, Heimberg $H$ : Beta cells can be generated from endogenous progenitors in injured adult mouse pancreas. Cell 2008, 132(2):197-207.

35. Cheng H, Wolfe SH, Valencia V, Qian K, Shen L, Phillips MI, Chang LJ, Zhang YC: Efficient and persistent transduction of exocrine and endocrine pancreas by adeno-associated virus type 8. J Biomed Sci 2007, 14(5):585-594.

36. Jimenez V, Ayuso E, Mallol C, Agudo J, Casellas A, Obach M, Munoz S, Salavert A, Bosch F: In vivo genetic engineering of murine pancreatic beta cells mediated by single-stranded adeno-associated viral vectors of serotypes 6, 8 and 9. Diabetologia 2011, 54(5):1075-1086.

37. Wang Z, Zhu T, Rehman KK, Bertera S, Zhang J, Chen C, Papworth G, Watkins S, Trucco M, Robbins PD, Li J, Xiao X: Widespread and stable pancreatic gene transfer by adeno-associated virus vectors via different routes. Diabetes 2006, 55(4):875-884.

38. Hong J, Behar J, Wands J, Resnick M, Wang LJ, DeLellis RA, Lambeth D, Souza RF, Spechler SJ, Cao W: Role of a novel bile acid receptor TGR5 in the development of oesophageal adenocarcinoma. Gut 2010, 59(2):170-180.

39. Steinstraesser L, Hirsch T, Beller J, Mittler D, Sorkin M, Pazdierny G, Jacobsen F, Eriksson E, Steinau HU: Transient non-viral cutaneous gene delivery in burn wounds. J Gene Med 2007, 9(11):949-955.

40. Zhang W, Zhang Y, Sood R, Ranjan S, Surovtseva E, Ahmad A, Kinnunen PK Pyykko I, Zou J: Visualization of intracellular trafficking of Math1 protein in different cell types with a newly-constructed nonviral gene delivery plasmid. J Gene Med 2011, 13(2):134-144.

41. Zhang Y, Song M, Cui ZS, Li CY, Xue XX, Yu M, Lu Y, Zhang SY, Wang EH, Wen YY: Down-regulation of TSG101 by small interfering RNA inhibits the proliferation of breast cancer cells through the MAPK/ERK signal pathway. Histol Histopathol 2011, 26(1):87-94.

42. Mahato RI, Henry J, Narang AS, Sabek O, Fraga D, Kotb M, Gaber AO: Cationic lipid and polymer-based gene delivery to human pancreatic islets. Mol Ther 2003, 7(1):89-100

43. Baeyens L, De Breuck S, Lardon J, Mfopou JK, Rooman I, Bouwens L: In vitro generation of insulin-producing beta cells from adult exocrine pancreatic cells. Diabetologia 2005, 48(1):49-57.

44. Saldeen J, Curiel DT, Eizirik DL, Andersson A, Strandell E, Buschard K, Welsh $\mathrm{N}$ : Efficient gene transfer to dispersed human pancreatic islet cells in vitro using adenovirus-polylysine/DNA complexes or polycationic liposomes. Diabetes 1996, 45(9):1197-1203.

45. Maurisse R, De Semir D, Emamekhoo H, Bedayat B, Abdolmohammadi A, Parsi H, Gruenert DC: Comparative transfection of DNA into primary and transformed mammalian cells from different lineages. BMC Biotechnol 2010, 10:9

46. Young AT, Lakey JR, Murray AG, Moore RB: Gene therapy: a lipofection approach for gene transfer into primary endothelial cells. Cell Transplant 2002, 11(6):573-582.

47. Zhang M, He W, Liu F, Zou P, Xiao J, Zhong ZD, Hu ZB: Inhibition of mouse hepatocyte apoptosis via anti-Fas ribozyme. World J Gastroenterol 2004, 10(17):2567-2570.

48. Uchida E, Mizuguchi H, Ishii-Watabe A, Hayakawa T: Comparison of the efficiency and safety of non-viral vector-mediated gene transfer into a wide range of human cells. Biol Pharm Bull 2002, 25(7):891-897.

49. Colin A, Faideau M, Dufour N, Auregan G, Hassig R, Andrieu T, Brouillet E, Hantraye P, Bonvento G, Deglon N: Engineered lentiviral vector targeting astrocytes in vivo. Glia 2009, 57(6):667-679.

50. Desmaris N, Bosch A, Salaun C, Petit C, Prevost MC, Tordo N, Perrin P, Schwartz O, de Rocquigny $\mathrm{H}$, Heard JM: Production and neurotropism of lentivirus vectors pseudotyped with lyssavirus envelope glycoproteins. Mol Ther 2001, 4(2):149-156.

51. Watson DJ, Kobinger GP, Passini MA, Wilson JM, Wolfe JH: Targeted transduction patterns in the mouse brain by lentivirus vectors pseudotyped with VSV, Ebola, Mokola, LCMV, or MuLV envelope proteins. Mol Ther 2002, 5(5 Pt 1):528-537.

52. MacKenzie TC, Kobinger GP, Kootstra NA, Radu A, Sena-Esteves M, Bouchard S, Wilson JM, Verma IM, Flake AW: Efficient transduction of liver and muscle after in utero injection of lentiviral vectors with different pseudotypes. Mol Ther 2002, 6(3):349-358.

53. MacKenzie TC, Kobinger GP, Louboutin JP, Radu A, Javazon EH, SenaEsteves M, Wilson JM, Flake AW: Transduction of satellite cells after prenatal intramuscular administration of lentiviral vectors. J Gene Med 2005, 7(1):50-58.

54. Hachiya A, Sriwiriyanont P, Patel A, Saito N, Ohuchi A, Kitahara T, Takema $Y$, Tsuboi R, Boissy RE, Visscher MO, Wilson JM, Kobinger GP: Gene transfer in human skin with different pseudotyped HIV-based vectors. Gene Ther 2007, 14(8):648-656

55. Auricchio A, Kobinger G, Anand V, Hildinger M, O'Connor E, Maguire AM, Wilson JM, Bennett J: Exchange of surface proteins impacts on viral vector cellular specificity and transduction characteristics: the retina as a model. Hum Mol Genet 2001, 10(26):3075-3081.

56. Bemelmans AP, Bonnel S, Houhou L, Dufour N, Nandrot E, Helmlinger D, Sarkis C, Abitbol M, Mallet J: Retinal cell type expression specificity of HIV-1-derived gene transfer vectors upon subretinal injection in the adult rat: influence of pseudotyping and promoter. J Gene Med 2005. 7(10):1367-1374.

57. Duisit G, Conrath H, Saleun S, Folliot S, Provost N, Cosset FL, Sandrin V, Moullier $P$, Rolling F: Five recombinant simian immunodeficiency virus pseudotypes lead to exclusive transduction of retinal pigmented epithelium in rat. Mol Ther 2002, 6(4):446-454

58. Limberis MP, Bell CL, Heath J, Wilson JM: Activation of transgene-specific T cells following lentivirus-mediated gene delivery to mouse lung. Mol Ther 2010, 18(1):143-150.

59. Kay MA, Li Q, Liu TJ, Leland F, Toman C, Finegold M, Woo SL: Hepatic gene therapy: persistent expression of human alpha 1-antitrypsin in mice after direct gene delivery in vivo. Hum Gene Ther 1992,

3(6):641-647.

60. Croyle MA, Callahan SM, Auricchio A, Schumer G, Linse KD, Wilson JM, Brunner $L$, Kobinger GP: PEGylation of a vesicular stomatitis virus $G$ pseudotyped lentivirus vector prevents inactivation in serum. J Virol 2004, 78(2):912-921.

61. DePolo NJ, Reed JD, Sheridan PL, Townsend K, Sauter SL, Jolly DJ, Dubensky TW Jr: VSV-G pseudotyped lentiviral vector particles produced in human cells are inactivated by human serum. Mol Ther 2000, 2(3):218-222.

62. Guibinga $\mathrm{GH}$, Friedmann T: Preparation of pseudotyped lentiviral vectors resistant to inactivation by serum complement. Cold Spring Harb Protoc 2010, 8:pdb prot5420.

63. Higashikawa F, Chang L: Kinetic analyses of stability of simple and complex retroviral vectors. Virology 2001, 280(1):124-131.

64. Chen X, Ji B, Han B, Ernst SA, Simeone D, Logsdon CD: NF-kappaB activation in pancreas induces pancreatic and systemic inflammatory response. Gastroenterology 2002, 122(2):448-457.

65. Chuah MK, Collen D, VandenDriessche T: Biosafety of adenoviral vectors. Curr Gene Ther 2003, 3(6):527-543. 
66. Durham HD, Lochmuller H, Jani A, Acsadi G, Massie B, Karpati G: Toxicity of replication-defective adenoviral recombinants in dissociated cultures of nervous tissue. Exp Neurol 1996, 140(1):14-20.

67. Braithwaite AW, Russell IA: Induction of cell death by adenoviruses. Apoptosis 2001, 6(5):359-370.

68. Barbu AR, Akusjarvi $\mathrm{G}$, Welsh $\mathrm{N}$ : Adenoviral-mediated transduction of human pancreatic islets: importance of adenoviral genome for cell viability and association with a deficient antiviral response. Endocrinology 2005, 146(5):2406-2414.

69. Zheng C, Goldsmith CM, O'Connell BC, Baum BJ: Adenoviral vector cytotoxicity depends in part on the transgene encoded. Biochem Biophys Res Commun 2000, 274(3):767-771.

70. He TC, Zhou S, da Costa LT, Yu J, Kinzler KW, Vogelstein B: A simplified system for generating recombinant adenoviruses. Proc Natl Acad Sci USA 1998, 95(5):2509-2514.

71. Zennou V, Petit C, Guetard D, Nerhbass U, Montagnier L, Charneau P: HIV-1 genome nuclear import is mediated by a central DNA flap. Cell 2000, 101(2):173-185.

72. Naldini L, Blomer U, Gage FH, Trono D, Verma IM: Efficient transfer, integration, and sustained long-term expression of the transgene in adult rat brains injected with a lentiviral vector. Proc Natl Acad Sci USA 1996, 93(21):11382-11388.

73. Castaing M, Guerci A, Mallet J, Czernichow P, Ravassard P, Scharfmann R: Efficient restricted gene expression in beta cells by lentivirus-mediated gene transfer into pancreatic stem/progenitor cells. Diabetologia 2005, 48(4):709-719.

74. Scherr M, Battmer K, Blomer U, Ganser A, Grez M: Quantitative determination of lentiviral vector particle numbers by real-time PCR. Biotechniques 2001, 31(3):520-522. 524, passim.

doi:10.1186/1472-6750-12-74

Cite this article as: Houbracken et al:: Gene delivery to pancreatic

exocrine cells in vivo and in vitro. BMC Biotechnology 2012 12:74.

\section{Submit your next manuscript to BioMed Central and take full advantage of:}

- Convenient online submission

- Thorough peer review

- No space constraints or color figure charges

- Immediate publication on acceptance

- Inclusion in PubMed, CAS, Scopus and Google Scholar

- Research which is freely available for redistribution 